\title{
Viscous-Resistance Calculation and Verification of Remotely Operated Inspection Submarine
}

\author{
Ardi Nugroho Yulianto ${ }^{1}$, Ketut Suastika ${ }^{1}$, and Aries Sulisetyono ${ }^{1}$
}

\begin{abstract}
The purpose of the present study is to calculate and verify the viscous resistance of a remotely operated inspection submarine which is used for the purpose of underwater in spections. The focus of the study is to investigate the effect of a vertical fin on the total value of the viscous resistance. In the design of a submarine, determination of the viscous resistance plays an important role. The smaller the viscous resistance, the smaller is the engine power to be required, which results in a more economic vehicle during the operation. Viscous resistance calculations were done by computational fluid dynamics (CFD) and verifications by wind tunnel experiments. Three models of submarines were simulated and tested. Results of data analysis show that the effect of an installation of a vertical fin on the total viscous resistance is not detectable in the current experimental setting. Furthermore, comparisons between simulation and experimental results show that the root mean square errors (RMSE) are, respectively, $2.48 \times 10^{-3}, 3.18 \times 10^{-3}$ and $2.88 \times 10^{-3}$ for model I, II and III.
\end{abstract}

Keywords - CFD, vertical fin, submarine, viscous resistance, wind tunnel.

\section{INTRODUCTION}

$\mathrm{S}^{\mathrm{e}}$ eventy percent of the surface area are water, so that he potential of the technology needs to get attention and to explore the potential that exists. The marine wealth of Indonesia is able to support Indonesian economy in the field of fisheries and marine. However, there are still many obstacles in tapping the potential that already exists.

Technology is a tool that needs to be developed to solve the various problems that occur. There is a methodology that has been developed for monitoring underwater conditions, ranging from conventional and using modern technology. The conventional method is done with traditional tools and submarines for high technology. Small-submarine is a vehicle that controlled using the remote control. However, these vehicles are still very expensive in terms of economy.

Many studies have developed the small-submarine. In 2009, the design was done as a small-submarine monitoring in coastal areas. This small-submarine is used to monitoring the problem of pollution and sewage in coastal areas. The beginning of this research has a small size with a length of 1 meter. This study also generated concerns about stability dynamics on underwater operation [ 1,2 ]. However, the journey was innovation in design small-submarine on the primary measure. This is done by considering the equipment that will be installed for operating without a crew. Many electronic equipment that will be installed for the purpose of the operation , such as cameras, wireless devices as data transfer, device control and navigational equipment. On the development of the mini-submarines, it is used by 2 meter length that changes the length of the previous study. It is made 1:1 scale model of the size. In the course of a study that analyzed numerically that a mini submarine has good hydrodynamic performance, which proved to chart the evolution of the movement that is

${ }^{1}$ Ardi Nugroho Yulianto, Ketut Suastika, and Aries Sulisetyono are with Department of Naval Architecture and Shipbuilding Engineering, Sepuluh Nopember Institute of Technology, Surabaya, 60111, Indonesia. E-mail: ardi09@mhs.na.its.ac.id. able to achieve a stable condition in less than 30 seconds Based on the analysis of dynamic control, the smallsubmarine able to reach a stable condition with a small time delay in time settle time is less than 10 seconds [3].

In this research, the process of designing the minisubmarines are concerned resistances that happened issues. The smaller resistance, the smaller is the engine power to be required, which results in a more economic vehicle during the operation. The main resistance is the viscous resistance that occurs in a small-submarine. Viscous resistance calculations uses computational fluid dynamics (CFD) and wind tunnel experiments.

\section{METHOD}

\section{A. Experiments}

Preparation of the model is done with the help of software modeling with AutoCAD. In the smallsubmarine models, Ithas a main dimension of length $2000 \mathrm{~mm}$, width $250 \mathrm{~mm}$, height $250 \mathrm{~mm}$. It consists of 3 variants. In wind tunnel experiments conducted 1:4 scale models of three-dimensional models. This process adjusts the scale of the equipment at the Laboratory of Fluid Mechanics Mechanical Engineering ITS. The following variations are shown in Figure 1, Figure 2 and Figure 3.

\section{B. CFD Simulation}

The CFD simulation process conducted on 3 variations according to figure 1, figure 2 and figure 3 . In general, Step of CFD process is done in three phase, namely Preprocessor, Processor/Solver and Post-processor. The preprocessor phase consists of flow input through the interface and then convert it into a appropriate form that required by solver section. Solver phase is the stage where preprocessor phase has finish. Estimate the unknown variables using simple functions.

\section{DRAG}

There are many studies that predict the amount of submarine power required to move the hull at a predetermined speed, or predict the speed thatgiven amount of power. The predictions have created on the basic of steady state conditions in level flight without a maneuvering that simple calculated. In the equation of 
motion, all of the wave equation can be removed because the assumption at level flight and without maneuvering, thereby reducing the coefficients because we assumed zero value [4]. The formula of drag is given by:

$\mathrm{R}_{\mathrm{T}}=\mathrm{R}_{\mathrm{BH}}+\mathrm{R}_{\mathrm{APP}}$

Where, $R_{T}$ is the total of resistance $(N)$, then $R_{B H}$ is a bare-hull resistance $(\mathrm{N}), \mathrm{R}_{\mathrm{APP}}$ is a resistance of appendages $(\mathrm{N})[4,5]$.

$\mathrm{R}_{\mathrm{BH}}=1 / 2 \simeq \mathrm{A} \mathrm{V}^{2} \mathrm{C}_{\mathrm{T}}$

Where $\rho$ is the density $\left(\mathrm{kg} / \mathrm{m}^{3}\right), \mathrm{A}$ is the area of the hull below the water $\left(\mathrm{m}^{2}\right), \mathrm{V}$ is the velocity of the smallsubmarines $(\mathrm{m} / \mathrm{s})$, and $\mathrm{C}_{\mathrm{T}}$ is the drag coefficient $[5,6]$. Drag coefficient was collected to particular reference area. The designers should be carefullyto use area. Drag coefficient $\left(\mathrm{C}_{\mathrm{T}}\right)$ can be obtained in 4 components, i.e.:

$\mathrm{C}_{\mathrm{T}}=\mathrm{C}_{f}+\mathrm{DC}_{f}+\mathrm{C}_{\mathrm{r}}+\mathrm{C}_{\mathrm{w}}$

$\mathrm{C}_{f}$ is the coefficient of frictional resistance. $\mathrm{DC}_{f}$ is correlation of permitted frictional resistance. $C_{r}$ is the residual resistance coefficient whose value depends on the type and shape of the vessel. $\mathrm{C}_{\mathrm{w}}$ is the coefficient of wave [7].

Basically the formula between $\mathrm{R}_{\mathrm{BH}}$ and $\mathrm{R}_{\mathrm{APP}}$ almost the same, the difference between bare-hull resistance and resistance of appendages is the coefficient of resistance $\left(\mathrm{C}_{\mathrm{T}}\right)$. In this case the price of $\mathrm{C}_{\mathrm{T}}$ by 0.005 [4].

\section{COMPUTATIONAL FLUID DYNAMIC}

Computational fluid dynamics (CFD) is the analysis of systems involvingfluid flow, heat transfer and associated phenomena such as chemical reactionsby means of computer-based simulation. The technique is very powerful andspans a wide range of industrial and nonindustrial application areas. Some examples: aerodynamics of aircraft and vehicles (lift and drag), hydrodynamics of ships, power plant (combustion in internal combustion engines and gas Turbines), turbo machinery (flows inside rotating passages), electrical and electronic engineering (cooling of equipment including micro circuits), chemical process engineering (mixing and separation, polymer molding), external and internal environment of buildings (wind loading and heating/ventilation), marine engineering (loads on offshore structures), environmental engineering (distribution of pollutants and effluents), hydrology and oceanography (flows in rivers, estuaries, oceans), meteorology (weather prediction), biomedical engineering (blood flows through arteries and veins) [8]. In CFD, the computer has important rolebecause it must perform millions of calculations to simulate the interaction of fluids and gases used in the field of engineering. We needs a high-technology to support tis simulations [9]. This is one aspect that continues to be addressed in the development of CFD methods. In summary, The CFD is a quantitative way to predict what will happen when the fluid flow and often a combination flow of heat transfer, phase change objects, chemical reactions, the movement of mechanical components, voltage and displacement that occurred in the structure of solid objects andsurrounding

In general, there are three steps that must be performed when performing CFD simulations, namely: preprocessor, processor and postprocessor. Preprocessor is the phase where the data is inserted starting from defining the domain as well as defining the boundary conditions. On the preprocessor phase, an object or a room that will be analyzed are divided by the number of a particular grid, are called meshing. Teh later phase is the stage where the processor do the counting process input data to equations involved in literatif, which shows the results of calculations performed to achieve the smallest error or convergent value. The calculation is done thoroughly the volume control to the process of integration of discrete equations. The Post-processor is the phase where the calculation results are interpreted into images, graphics, animation and even to certain color patterns [10].

There is the important thing in CFD for industry. The CFD analysis can be done on a system by reducing the cost of experiments, which takes a long time to do a test in a laboratory. Another thing that underlies the use of the concept of CFD is a deeper understanding of a problem to be solved. In this case a greater understanding of the fluid flow characteristics by looking at the results in the form of graphics, vector, contour and animation.

\section{WIND TUNNEL EXPERIMENT}

Wind tunnel is used to study the effects of air flow through solid objects. Currently, The wind tunnel testing has been widely applied on cars, aerofoil and other specimens . There are two basic types of wind tunnel, the open circuit tunnel and closed circuit tunnel. Based on air speed, wind tunnel is divided in to subsonic wind tunnel (Mach number $<1$ ), transonic wind tunnel (Mach number = 1), supersonic wind tunnel (Mach number $>$ 1), hypersonic wind tunnel (Mach number > 5) [11].In this research, experiments were conducted in an open circuit tunnel with type subsonic wind tunnel with a capacity of air velocity between $20 \mathrm{Hertz}$ to $50 \mathrm{Hertz}$. The wind tunnel has a length of $2980 \mathrm{~mm}$ with a square test section measuring $300 \times 300 \mathrm{~mm}^{2}$ and a length of $450 \mathrm{~mm}$. The Measurements were made using a scale aerodynamic forces ( aerodynamic force balance ) which has a precision of $1 \mathrm{mN}$. The small-submarine models have major size with a length of $2000 \mathrm{~mm}$, width 250 $\mathrm{mm}$, height $250 \mathrm{~mm}$. And then, The models are variated into 3 vertical fin variations. In the wind tunnel experiments, It is conducted 1:4 scale models of threedimensional models. This process adjusts the scale of the equipment at the Laboratory of Fluid Mechanics and Mechanical Engineering ITS. These are step in the testing process in the wind tunnel:

\section{A. Equipment of Wind Tunnel}

The tests were conducted at the Laboratory of Fluid Mechanics and Mechanical Engineering ITS using type subsonic wind tunnel as figure 4 which has a relatively low minimum speed. It has the lowest speed of $8 \mathrm{~m} / \mathrm{s}$ and the highest speed at $18 \mathrm{~m} / \mathrm{s}$.

\section{B. Model Preparation}

The models were created in the Laboratory of Fluid Mechanics and Mechanical Engineering ITS. It used material from PVC pipe (PVC), which can be seen in Figure 5. 


\section{Testing in Wind Tunnel}

The variations is made 3 variations of the model submarine and 5 speed variation, which is $8 \mathrm{~m} / \mathrm{s}, 10 \mathrm{~m} / \mathrm{s}$, $12 \mathrm{~m} / \mathrm{s}, 15 \mathrm{~m} / \mathrm{s}$ and $18 \mathrm{~m} / \mathrm{s}$. In figure 3, It shows the tests performed with the speed of $8 \mathrm{~m} / \mathrm{s}$ are listed on themanometer. which can be seen in Figure 6.

Figure 7 shows speed when testing at a speed of $8 \mathrm{~m} / \mathrm{s}$. It shows the measured frequency of $21.29 \mathrm{~Hz}$ and current of $2.8 \mathrm{~A}$. Increasing of speed can change the frequency and current in this.

Figure 8 shows the equipment that used to perform the measurements. It has the precision 0.01 that called forcebalancing. Figure 8 shows drag measurement that occurs on the speed $8 \mathrm{~m} / \mathrm{s}$. From the results of measurements, it shows $0.096 \mathrm{~N}$ for drag.

\section{ANALyZE BETwEen CFD AND Wind TUNNEL METHOD}

The comparison between wind tunnel experiments and simulation of computational fluid dynamics can be seen in Figure 9 to Figure 13 and Table 1 to Table 4.

Figure 9 shows that there is a difference of drag coefficient at variation of Reynolds number I, II and III. On each variation has a relatively constant value of $\mathrm{C}_{\mathrm{T}}$ for increasing of Reynolds numbers. From Figure 9, it didn't show a significant difference of $\mathrm{C}_{\mathrm{T}}$. Variations of the vertical find didn't give a great influence on the value of drag coefficient $\left(\mathrm{C}_{\mathrm{T}}\right)$. So that, the value of the total resistance of the three variations doesn't provide a significant difference.

Figure 10 shows a difference of drag coefficient and Reynolds number on variations I, II and III. On each variation, It has relatively decrease to the change of Reynolds numbers on value of $\mathrm{C}_{\mathrm{T}}$. Figure 10 shows that increasing of Reynolds number cause decreasing at drag coefficient value on all variation I, II and III.

Figure 11 and data in Table 1, it can be seen that there is a difference between the results of wind tunnel testing and Computational Fluid Dynamics (CFD). At a speed of $8 \mathrm{~m} / \mathrm{s}$ with Reynolds number ( $\operatorname{Re})$ 262222, there is a difference between wind tunnel testing to CFD simulation in the amount of $13.020 \%$. And then at a speed of $10 \mathrm{~m} / \mathrm{s}$ with Re 327777 , there is a difference between wind tunnel testing to CFD simulations in the amount of $1.627 \%$. At a speed of $12 \mathrm{~m} / \mathrm{s}$ with Reynolds numbers 393333, there is a difference between wind tunnel testing to CFD simulation in the amount of $9.405 \%$. At a speed of $15 \mathrm{~m} / \mathrm{s}$ to $\operatorname{Re} 491666$, there is a difference between wind tunnel testing to CFD simulations in the amount of $17.089 \%$. And then at a speed of $18 \mathrm{~m} / \mathrm{s}$ withRe 590000 , there is a difference between wind tunnel testing to CFD simulations of $18.637 \%$.

Figure 12 and data in Table 2, it can be seen that there is a difference between the results of wind tunnel testing and Computational Fluid Dynamics (CFD). At a speed of $8 \mathrm{~m} / \mathrm{s}$ with Reynolds number $(\mathrm{Re}) 262222$, there is a difference between wind tunnel testing to CFD simulation in the amount of $7.724 \%$. And then at a speed of $10 \mathrm{~m} / \mathrm{s}$ with $\operatorname{Re} 327777$, there is a difference between wind tunnel testing to CFD simulations in the amount of $0.254 \%$. At a speed of $12 \mathrm{~m} / \mathrm{s}$ with Reynolds numbers 393333 , there is a difference between wind tunnel testing to CFD simulation in the amount of $7.503 \%$. At a speed of $15 \mathrm{~m} / \mathrm{s}$ to $\operatorname{Re} 491666$, there is a difference between wind tunnel testing to CFD simulations in the amount of $13.160 \%$. And then at a speed of $18 \mathrm{~m} / \mathrm{s}$ withRe 590000 , there is a difference between wind tunnel testing to CFD simulations of $18.218 \%$.

Figure 13 and data in Table 3, it can be seen that there is a difference between the results of wind tunnel testing and Computational Fluid Dynamics (CFD). At a speed of $8 \mathrm{~m} / \mathrm{s}$ with Reynolds number $(\operatorname{Re}) 262222$, there is a difference between wind tunnel testing to CFD simulation in the amount of $17.446 \%$. And then at a speed of $10 \mathrm{~m} / \mathrm{s}$ with $\operatorname{Re} 327777$, there is a difference between wind tunnel testing to CFD simulations in the amount of $3.570 \%$. At a speed of $12 \mathrm{~m} / \mathrm{s}$ with Reynolds numbers 393333, there is a difference between wind tunnel testing to CFD simulation in the amount of $2.372 \%$. At a speed of $15 \mathrm{~m} / \mathrm{s}$ to $\operatorname{Re} 491666$, there is a difference between wind tunnel testing to CFD simulations in the amount of $10.988 \%$. And then at a speed of $18 \mathrm{~m} / \mathrm{s}$ withRe 590000 , there is a difference between wind tunnel testing to CFD simulations of $17.692 \%$.

In table 4 can be seen that the percentage of error rate data between wind tunnel testing to CFD simulation on variation $\mathrm{I}$ in the amount of $9.372 \%$ that are categorized as to a very good criteria. Then the second variation of $11.956 \%$ that are categorized as to a good criteria. Then in the third variation of $10.413 \%$ that also are categorized as to a good criteria.

\section{CONCLUSION}

The addition of the vertical fin and the setting position not significantly affect onvalue of $\mathrm{C}_{\mathrm{T}}$. The lowest of $\mathrm{C}_{\mathrm{T}}$ is 0.0209 for Re 262222 in the thirdvariation. The highest of $\mathrm{C}_{\mathrm{T}}$ is 0.0233 for $\mathrm{Re} 262222$ in the second variation. At the wind tunnel testing and CFD simulations show the value of root mean square error (RMSE) on the first variation of $2.48 \times 10^{-3}$, the second variation of $3.18 \times$ $10^{-3}$, the third variation of $2.88 \times 10^{-3}$. The rate of percentage error on wind tunnel testing and CFD simulation are $9.37 \%$ in the first variation, $11.96 \%$ in the second variation, $10.41 \%$ in the third variation.

\section{ACKNOWLEDGEMENT}

Acknowledgements from author gives to Mr. Wawan Aries Widodo as secretary of the Department of Mechanical Engineering ITS has provided an opportunity to used The Machine and Fluid Mechanics Laboratory. Graduate Scholarship Program ITS fresh graduate who has provided financial support. Mr. Nur and Mr. Tris who have helped in the creation and testing of models. Cahyono Fajri Wibowo, M. Andi Firdiansyah and Ricky Fadhilla who have helped in the process of laboratory testing as well as friends that we can't mention one by one.

\section{REFERENCES}

[1] A. Sulisetyono and D. Purnomo, "The Mini-Submarine Design for Monitoring of the Pollutant and Sewage Discharge in Coastal Area", $5^{\text {th }}$ International Conference on Asian and Pacific Coasts, Singapore: NTU, 2009. 
[2] A. Sulisetyono, "Dynamics Stability Prediction of the MiniSubmarine in Underwater Mission", Seminar Nasional Pascasarjana IX, Surabaya: ITS, 2009.

[3] A. Prisdianto and A. Sulisetyono, Perancangan ROV dengan Hydrodinamic Performance yang Baik untuk Misi Monitoring Bawah Laut, Surabaya: ITS, 2012.

[4] E.E. Allmendinger, Submersible Vehicle Systems Design, Jersey: SNAME, 1990

[5] E. Lewis, Principles of Naval Architecture Second Revision.Jersey: SNAME, 1988.

[6] J.S. Carlton, Marine Propeller sand Propulsion, London: Elsevier, 2006

[7] A.F. Molland, S.R. Tunock, and D.A. Hudson, Ship Resistance and Propulsion, New York: Cambridge University Press, 2011.

[8] H.K. Versteeg, an Introduction to Computational Fluid Dynamics, England: Pearson Education Limited, 2007.

[9] D. Kuzmin, Introduction to Computational Fluid Dynamics, Institute of Applied Mathematics University of Dortmund,http://www.mathematik.uniDortmund.de/_kuzmin/cfdi ntro/cfd.html.

[10] A.J. Shaughnessy, I.M. Katz, and J.P. Schaffer, Introduction to Fluid Mechanics. NewYork: Oxford University Press, 2005.

[11] J.D. Pereira, Wind Tunnels Aerodynamics, Models and Experiments. New York: Nova Science Publishers, 2011.

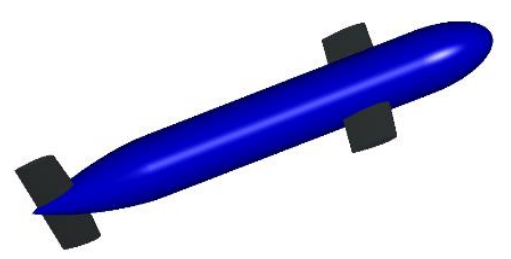

Figure 1. Submarine variation I

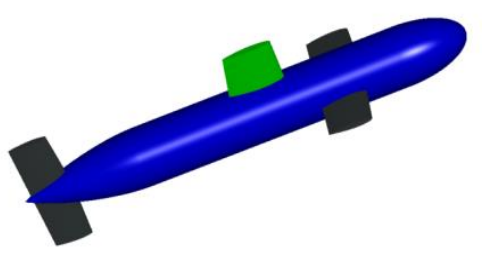

Figure 2. Submarine variation II

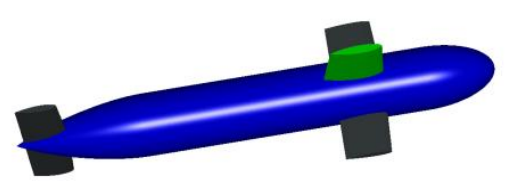

Figure 3. Submarine variation III

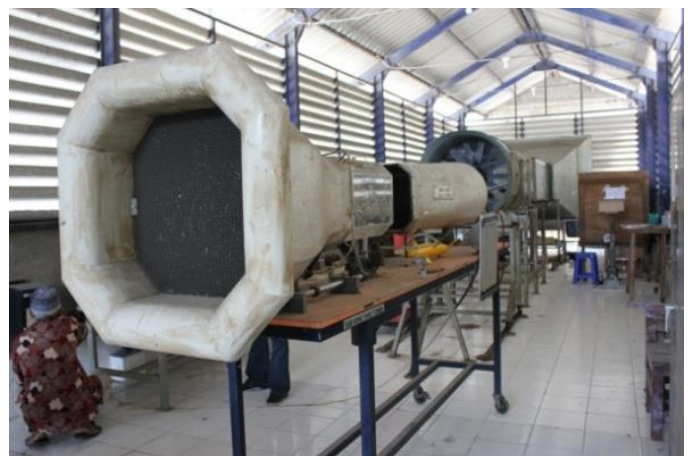

Figure 4. Subsonic Wind Tunnel

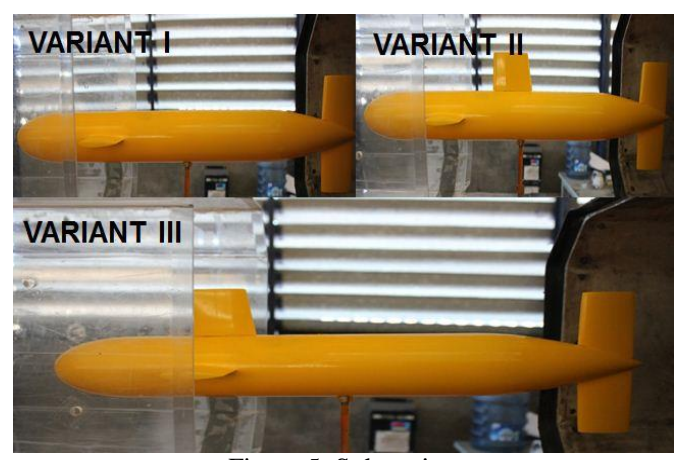

Figure 5. Submarine

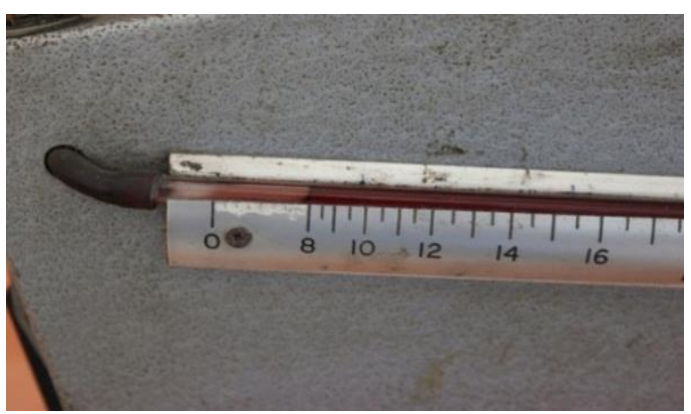

Figure 6. Speed of $8 \mathrm{~m} / \mathrm{s}$ in the manometer

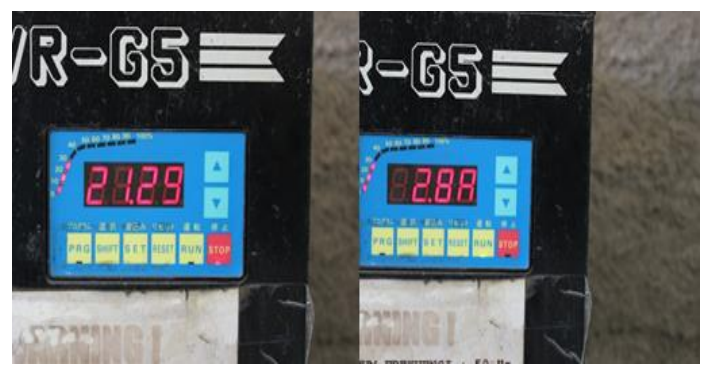

Figure 7. Flow Control Equipment and Frequency

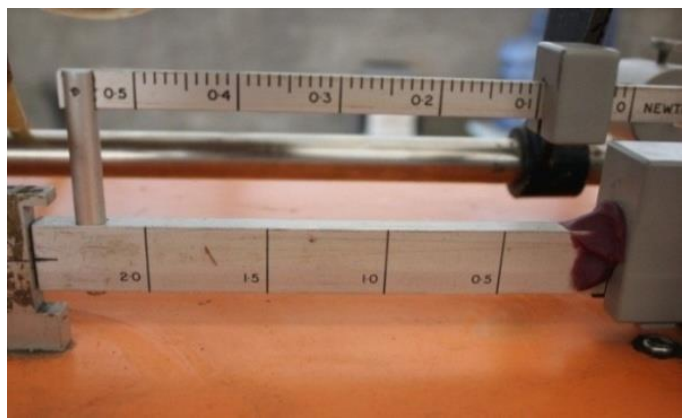

Figure 8. Force Balancing 


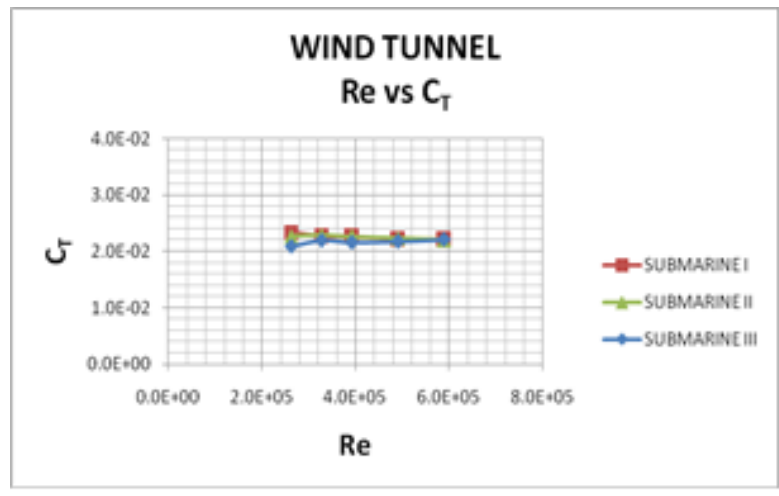

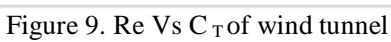

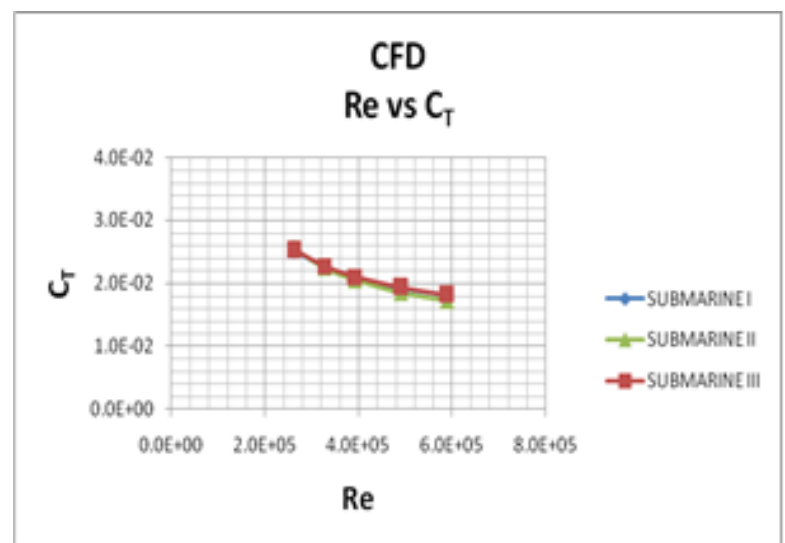

Figure 10. Re $\mathrm{Vs}_{\mathrm{T}} \mathrm{C}_{\mathrm{T}}$ of CFD

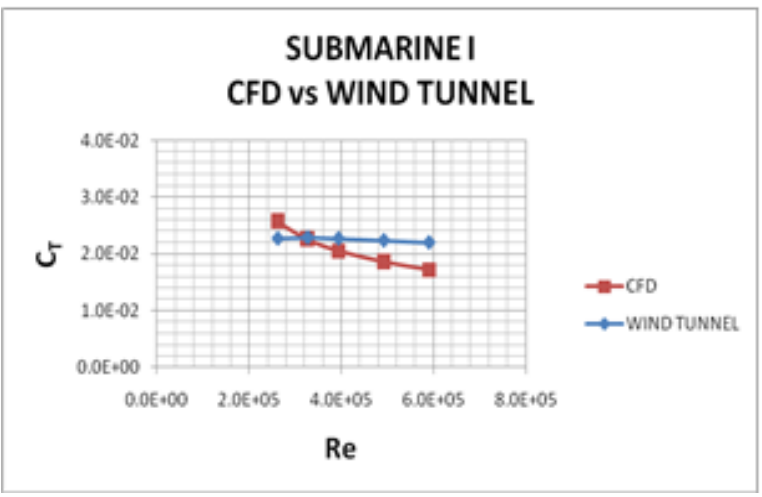

Figure 11. Re Vs $\mathrm{C}_{\mathrm{T}}$ Submarine I

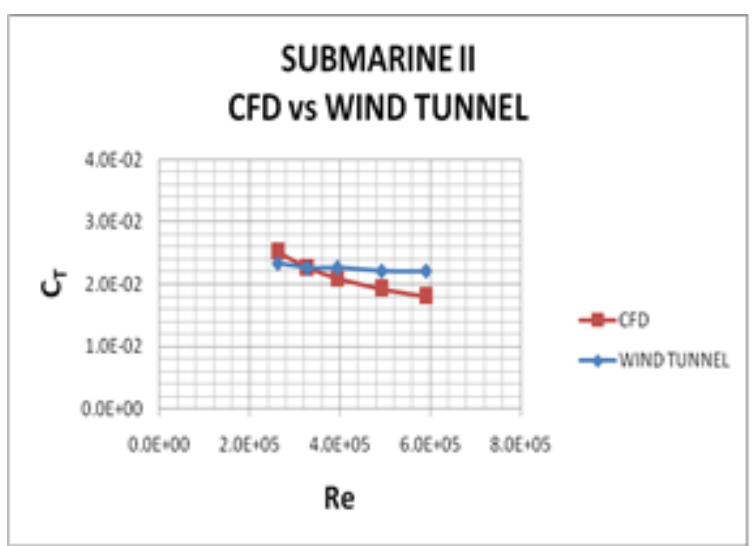

Figure 12. Re $\mathrm{Vs} \mathrm{C}_{\mathrm{T}}$ of submarine II

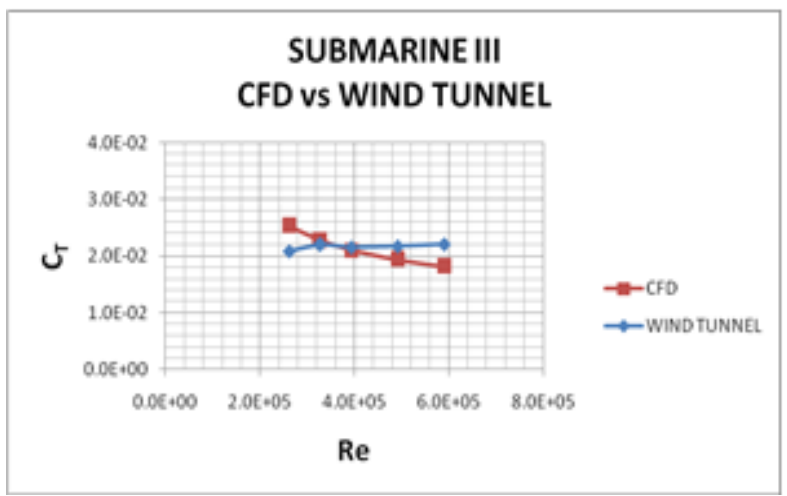

Figure 13. Re $\mathrm{Vs} \mathrm{C}_{\mathrm{T}}$ of submarine III

TABLE 1.

COMParison BETWEen Wind TunNel TESTING AND CFD VARIATIONS I

\begin{tabular}{cccccc}
\hline & & & & $\mathrm{C}_{\mathrm{T}}$ \\
No & Speed $(\mathrm{m} / \mathrm{s})$ & $\mathrm{Re}$ & $\mathrm{CFD}$ & $\begin{array}{c}\text { Wind } \\
\text { Tunnel }\end{array}$ & $\begin{array}{c}\text { Difference } \\
(\%)\end{array}$ \\
\hline 1 & 8 & $2.62 \mathrm{E}+05$ & 0.0256 & 0.0227 & 13.019 \\
2 & 10 & $3.28 \mathrm{E}+05$ & 0.0225 & 0.0229 & 1.627 \\
3 & 12 & $3.93 \mathrm{E}+05$ & 0.0205 & 0.0227 & 9.405 \\
4 & 15 & $4.92 \mathrm{E}+05$ & 0.0186 & 0.0224 & 17.089 \\
5 & 18 & $5.90 \mathrm{E}+05$ & 0.0172 & 0.0220 & 18.637 \\
\hline
\end{tabular}

TABLE 2.

COMPARISON BETWEEN WIND TUNNEL TESTING AND CFD VARIATIONS II

\begin{tabular}{cccccc}
\hline \hline No & Speed (m/s) & $\operatorname{Re}$ & $\begin{array}{c}\mathrm{C}_{\mathrm{T}} \\
\mathrm{CFD}\end{array}$ & $\begin{array}{c}\mathrm{C}_{\mathrm{T}} \\
\text { Wind } \\
\text { Tunnel }\end{array}$ & $\begin{array}{c}\text { Difference } \\
(\%)\end{array}$ \\
\hline 1 & 8 & $2.62 \mathrm{E}+05$ & 0.0252 & 0.0234 & 7.724 \\
2 & 10 & $3.28 \mathrm{E}+05$ & 0.0226 & 0.0227 & 0.254 \\
3 & 12 & $3.93 \mathrm{E}+05$ & 0.0209 & 0.0226 & 7.503 \\
4 & 15 & $4.92 \mathrm{E}+05$ & 0.0192 & 0.0221 & 13.160 \\
5 & 18 & $5.90 \mathrm{E}+05$ & 0.0181 & 0.0221 & 18.218 \\
\hline \hline
\end{tabular}

TABLE 3.

COMPARISON BETWEEN WIND TUNNEL TESTING AND CFD VARIATIONS III

\begin{tabular}{cccccc}
\hline No & Speed $(\mathrm{m} / \mathrm{s})$ & $\mathrm{Re}$ & $\begin{array}{c}\mathrm{C}_{\mathrm{T}} \\
\mathrm{CFD}\end{array}$ & $\begin{array}{c}\mathrm{C}_{\mathrm{T}} \\
\text { Wind } \\
\text { Tunnel }\end{array}$ & $\begin{array}{c}\text { Difference } \\
(\%)\end{array}$ \\
\hline 1 & 8 & $2.62 \mathrm{E}+05$ & 0.0253 & 0.0209 & 17.446 \\
2 & 10 & $3.28 \mathrm{E}+05$ & 0.0227 & 0.0220 & 3.570 \\
3 & 12 & $3.93 \mathrm{E}+05$ & 0.0210 & 0.0216 & 2.372 \\
4 & 15 & $4.92 \mathrm{E}+05$ & 0.0193 & 0.0217 & 10.988 \\
5 & 18 & $5.90 \mathrm{E}+05$ & 0.0182 & 0.0221 & 17.692 \\
\hline \hline
\end{tabular}

TABLE 4

EVALUATION BETWEEN CFD AND WIND TUNNEL

\begin{tabular}{ccccc}
\hline No & Variation & MSE & RMSE & $\begin{array}{c}\text { MAPE } \\
(\%)\end{array}$ \\
\hline 1 & Submarine I & $6.17 \mathrm{E}-06$ & $2.48 \mathrm{E}-03$ & 9.372 \\
2 & Submarine II & $1.01 \mathrm{E}-05$ & $3.18 \mathrm{E}-03$ & 11.956 \\
3 & Submarine III & $8.28 \mathrm{E}-06$ & $2.88 \mathrm{E}-03$ & 10.413 \\
\hline \hline
\end{tabular}

